\title{
The Mediterranean Water Tongue and Its Chlorofluoromethane Signal in the Iberian Basin in Early Summer 1989
}

\author{
H.-H. HinRichsen, M. Rhein, R. H. KäSE, AND W. ZenK \\ Institut für Meereskunde an der Universität Kiel, Kiel, Germany
}

\begin{abstract}
Hydrographic observations from the Iberian Basin demonstrate the variability of water masses in upper and intermediate layers. The surveyed area embraces the internal front between water masses from higher latitudes and the Mediterranean outflow, exhibits several isolated Mediterranean eddy (meddy) structures at middepth, and displays the virtual source region for the Mediterranean Water (MW) tongue off the Portuguese continental slope. The description is enhanced by additional chlorofluoromethane measurements, which show anomalously high concentrations at middepth, due to mixing of MW with the overlying Atlantic waters in the Gulf of Cadiz. The geostrophic stream function shows several meddylike features that not only are remarkably extended in the depth range of the MW, but are also correlated with surface height anomalies.
\end{abstract}

\section{INTRODUCTION}

It is well established that the region west of the Portuguese continental slope hosts a significant warm and salty water reservoir, necessary for the permanent existence of the Mediterranean Water (MW) in the North Atlantic. This water mass represents a mixture of outflowing Gibraltar water, North Atlantic Central Water, and North Atlantic Deep Water. After entering the Gulf of Cadiz, MW propagates westward as an undercurrent or contour current following miscellaneous topographic features such as the subshelf regions south of the Algarve coastline in the Gulf of Cadiz. Further downstream the undercurrent penetrates through distinct channels deeper down to its equilibrium depth between 500 and $1500 \mathrm{~m}$. From there on, two stacked outflow cores follow a complex spreading pattern on two preferred density levels [Ambar and Howe, 1979; Rhein and IInrichsen, 1993]; the transient existence of a third shallower core was detected between 400 and $700 \mathrm{~m}$ [Ambar, 1983]. The MW in the northeastern Atlantic is generally parameterized as a large-scale tongue of intermediate water, balanced by a constant ratio of slow advection and turbulent diffusion [Richardson and Mooney, 1975].

Observational results and a number of theoretical studies from the past 10 years have revealed the frequent existence of highly energetic intrathermocline vortices, called meddies [Richardson et al., 1991]. These self-contained, slowly drifting eddies preserve their original heat and salt content together with their potential vorticity over hundreds of kilometers [Armi et al., 1989]. Several areas for meddy generation have been suggested in the past. Among them are the Gulf of Cadiz [Prater and Sanford, 1990; Rhein and Hinrichsen, 1993] and the deep Iberian Basin midway between the Azores and the continental slope of Portugal [Käse et al., 1989].

The latter region was subject to an intensive hydrographic survey from board of R/V Poseidon in early summer 1989. Among the aims of this Poseidon 159 cruise were a synoptic conductivity-temperature-depth (CTD) survey, enhanced by oxygen and chlorofluoromethane (CFM, compounds F1I

Copyright 1993 by the American Geophysical Union.

Paper number 93JC00040.

0148-0227/93/93JC-00040\$05.00 and F12) samples, of the eastern Iberian Basin with its reservoir of highly saline $\mathrm{MW}$, and the deployment of underwater sound sources as the base for future Lagrangian current observations within the MW tongue. The grid was refined where features like meddies or meanders were encountered at the periphery of the inner region (core salinity $>36.2 \mathrm{psu}$ ) of $\mathrm{MW}$. We have obtained a quasi-synoptic hydrographic survey containing 99 CTD stations, including a reasonable coverage of discrete oxygen and CFM samples from 63 stations (Figure 1). The total survey lasted from May 24 to June 20, 1989.

After the discussion of methods we present a series of characteristic parameter distributions on a cross section between the northwestern corner of the survey area and the source region of MW off southwestern Portugal. The characteristics of the CFM data follow next. Horizontal charts and averaged vertical profiles are used to distinguish between characteristic water masses and their specific properties.

\section{Methods and Data Sets}

While acquisition and reduction of CTD data were identical with those from the 1988 campaign of R/V Poseidon in the same region [Käse et al., 1989], in 1989 we were able to collect CFM data from the MW tongue in the Iberian Basin. Two CFM compounds, F11 and F12, were measured, following basically the procedures described by Bullister and Weiss [1988]: about $30 \mathrm{~mL}$ of water are transferred from precleaned Niskin bottles to a purge and trap system. The two components F11 and F12 are then separated and detected with gas chromatography electron capture detection techniques. From the beginning the system showed a decreasing F11 blank, starting from station 531 with $\mathrm{F} 11=0.13$ $\mathrm{pmol} / \mathrm{kg}$ and getting $<0.02 \mathrm{pmol} / \mathrm{kg}$ at station 563 . The blank has been determined at least twice for each station and subtracted from the measured concentrations. A necessary change of a connection unit in the purge and trap system lead to a permanent $\mathrm{F} 12$ blank of $0.07 \pm 0.04 \mathrm{pmol} / \mathrm{kg}$ which could not be removed. The poor reproducibility of \pm 0.04 $\mathrm{pmol} / \mathrm{kg}$ for Fll of the seawater measurements was caused not only by the unusually high blanks, but also by problems in integrating the peaks due to erratic variations in the baseline of the chromatographs. These difficulties were more 


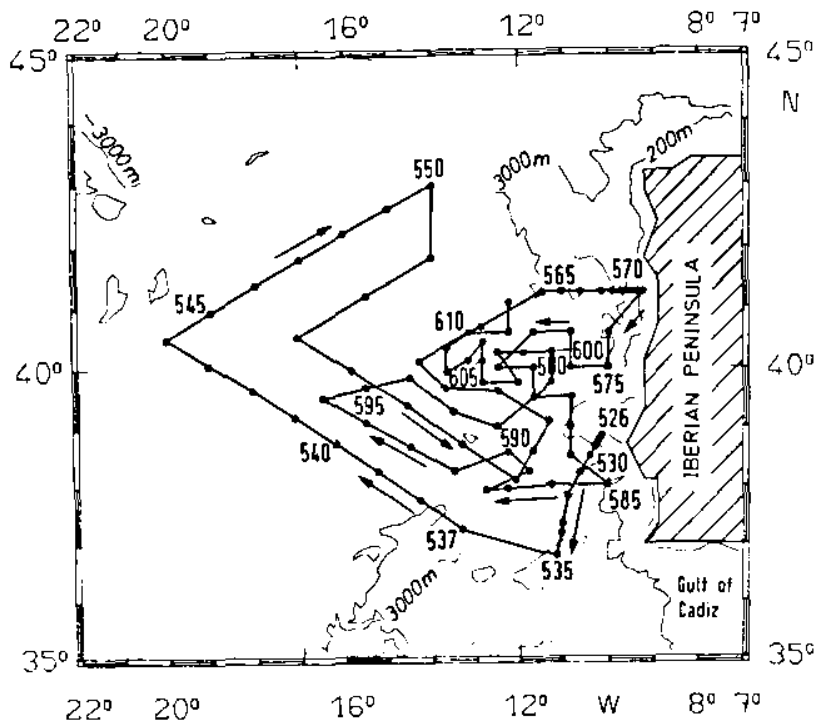

Fig. 1. Cruise track of hydrographic survey R/V Poseidon 159 , legs 1 and 2, May-June 1989, showing CTD stations (dots).

severe for F12; therefore we restrict ourselves to a discussion of F11 data only. Owing to cooling problems of the purge and trap system, a number of stations near the continental shelf are missing. Some others had to be skipped because of too short time lags between sequential casts. The gas standard used was calibrated absolutely by John Bullister (Pacific Marine Environmental Laboratory, Seattle, Washington) against the Scripps Institute of Oceanography scale.

The CFMs F11 and F12 are suitable tracers to study water mass formation and circulation up to decadal time scales for several reasons: They have no natural sources and they are inert in the troposphere and the ocean. They are transported into the ocean's interior by deep water formation. The increasing $\mathrm{F} 11 / \mathrm{F} 12$ ratio prior to $\mathrm{CFM}$ regulations in the mid-1970s has been used as a tool to determine the "age" of a water mass, i.e., the time since it left the surface [Weiss et al., 1985]. In addition, water recently in contact with the air contains significant levels of CFMs due to high present-day CFM concentrations. The level of a water mass away from the surface can be a measure of its ventilation rate [Bullister and Weiss, 1983; Rhein, 1991]. In contrast to water masses ventilated by convection, the $M W$ tongue in the Atlantic obtains most of its CFM signal in the Gulf of Cadiz by entrainment of overlying CFM-rich North Atlantic Central Water [Rhein and Hinrichsen, 1993]. These quasi-persistent admixture obscures any age information. CFM measurements in the Alboran Sea and in the Gulf of Cadiz exhibit similar F11/F12 ratios for Gibraltar Water and North Atlantic Central Water, so CFM concentrations in the undercurrent are highly dependant on the depth region of North Atlantic Central Water which was mixed with MW.

\section{Characteristic Hydrographic Sections}

Figure 2 displays synoptic views of the heterogenity of water masses, which are representative for the upper and intermediate layers of the Iberian Basin. For the cross sections of potential temperature, salinity, oxygen, and F11 (Figures $2 a, 2 b, 2 c$, and $2 d$, respectively), we have chosen a section composed of stations connecting the northwestern side of our surveyed area (Figure 1) with its southeastern corner off southwestern Portugal. It was selected because
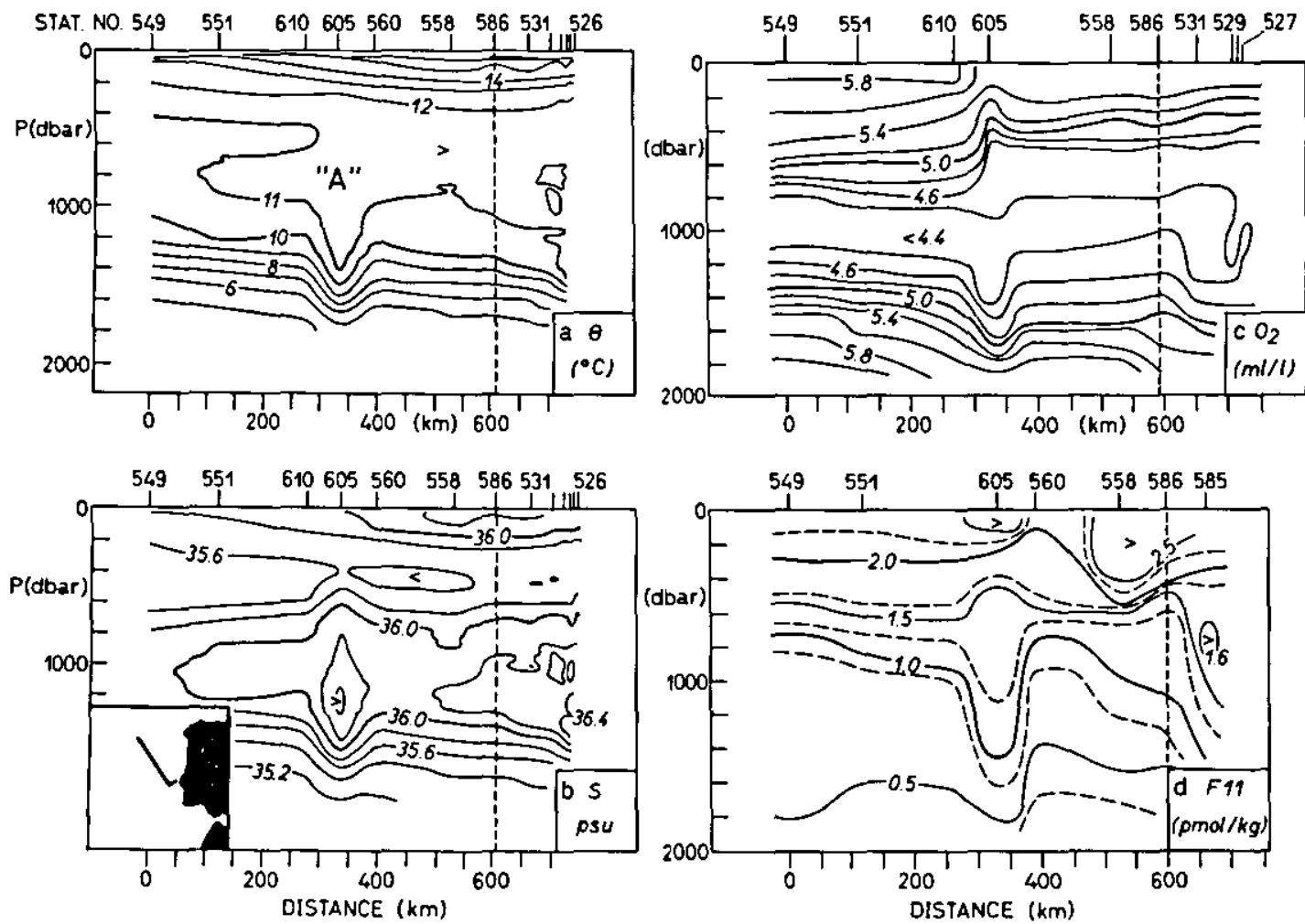

Fig. 2. Hydrographic sections across the Iberian Basin: $(a)$ potential temperature, $(b)$ salinity, $(c)$ oxygen, and $(d)$ F11. 
this section (1) nearly perpendicularly cuts the internal front between waters from higher latitude, i.e., Labrador Sea and MW (hereinafter LM front), (2) includes a prominent warm and salty feature, called meddy $A$, and (3) resolves structures off the Portuguese continental slope representing a source for the spreading of the MW tongue.

At station 586 the southeastern parts of Figures $2 a$ through $2 c$ contain a change in direction of about $90^{\circ}$ which allows for a better resolution of the temperature, salinity, and oxygen stratification on the southern slope of the Tejo Plateau. As a result of the mentioned technical problems, no simultaneous F1I data are available from this southern end of our cross-basin section. Instead, we have chosen a slightly different section for CFM (Figure $2 d$ ). The easternmost CFM station (station 585 ) lies only about $60 \mathrm{~km}$ south of station 531 on the continental slope (compare Figures 1 and 2). The low surface temperatures $\left(<17^{\circ} \mathrm{C}\right)$ off Portugal on the right sides of Figure $2 a$ may be easily explained by upwelling processes which are confirmed by lower salinities (36.0 psu) on the continental slope (Figure $2 b$ ). Highest surface temperatures and salinities occur at the southernmost station $531\left(\theta>18^{\circ} \mathrm{C}, S>36.2 \mathrm{psu}\right)$, which apparently resembles more subtropical conditions found in the Canary Basin. Toward the southeast, oxygen (Figure $2 c$ ) shows a systematic decrease in surface waters from $>5.8$ to $5.4 \mathrm{~mL} / \mathrm{L}$, while F1l (Figure $2 d$ ) displays the opposite trend in the upper water column, increasing from 2.2 to $2.7 \mathrm{pmol} / \mathrm{kg}$. The former could be caused by decreasing solubility and higher biological activity near the continental shelf. The high CFM values here could be influenced by higher atmospheric CFM concentrations compared with open ocean conditions.

Thermocline waters at intermediate depth in general are characterized by a uniform decrease with depth in temperature, salinity, oxygen, and F11 values. Down to the 500- to 600-dbar range, highly correlated temperature and salinity gradients reflect the presence of Eastern North Atlantic Central Water [Emery and Meincke, 1986]. Horizontal gradients at the northwestern side indicate some admixtures of freshly ventilated Subpolar Mode Water, well reflected by higher oxygen (Figure $2 c$ ), less stratified FII values (Figure $2 d$ ), and low potential vorticity values (not shown) in the 300 -dbar range. The salinity minimum around 400 dbar represents the upper boundary of the $\mathrm{MW}$ tongue occupying the water column down to about 1400 dbar.

The LM front is seen in the northwest between stations 549 and 551, separating thermally more stratified waters from nearly homothermal waters further east. Both water masses represent the background field for salty intrathermocline eddies in the respective region, demonstrated in case of Figure 2 by the warm meddy $A$ at station 605 . In the given example we recognize that temperature $\left(>11.0^{\circ} \mathrm{C}\right)$ and $\mathrm{F} 11$ $(>1.25 \mathrm{pmol} / \mathrm{kg}$ ) signals are particularly well expressed in the 700-dbar level, while salinity has its intermediate maximum (>36.4 psu) at $1200 \mathrm{dbar}$. The slope water area, northeast (in case of F1l east) of station 532 (585) is occupied by interleaving water masses, which in addition show the welldocumented separation into an upper $(\mathrm{Mu})$ and a lower $(\mathrm{Ml})$ core of MW (Figure 3). Only here near the continental slope we find in the upper core the characteristic high oxygen and F11 content, which both indicate recent and enhanced mixing with upper North Atlantic Central Water [Rhein and Hinrichsen, 1993]. The mixing path can be traced backward toward Cape São Vicente and further east toward the Gulf of Cadiz.

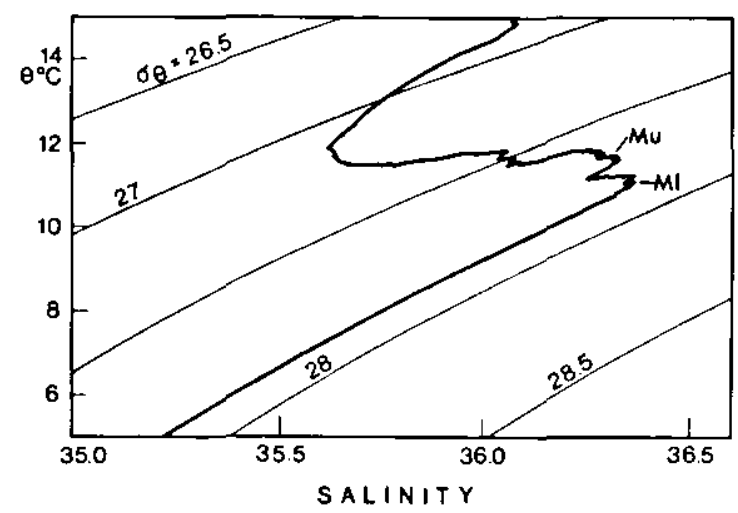

Fig. 3. Averaged $\theta / S$ diagram of the slope water area (stations 526-532).

Layers underneath the MW level are of less interest here. The water column is occupied by colder $\left(<5^{\circ} \mathrm{C}\right)$ and fresher $(<35.2 \mathrm{psu})$ North Atlantic Deep Water, which is poor in FII $(<0.5 \mathrm{pmol} / \mathrm{kg})$ and well oxygenated $(>5.6 \mathrm{ml} /)$. This oxygen level is identical with near surface values.

\section{HydROGRAPHY OF MEDdIES AND TIIE BACKGROUND FIELD}

In the following the characteristics of background regions with minor MW influence (station 548, northwestern corner) are compared with property distributions inside two meddies, called $A$ and $B$. In addition, we discuss the source region near the southeastern Iberian shelf where we expect the reservoir of $\mathrm{MW}$ (station 585).

Apparently, the MW tongue plays an important role in determining the CFM tracer field in the Iberian Basin (Figures $4 a$ and $4 b$ ). Vertical FII profiles (Figure $4 a$ ) show largest differences in the depth range between 500 and 1400 dbar. The intermediate F11 maximum is most prominent near the southeastern Iberian shelf around $800 \mathrm{dbar}$ (station 585) followed by the F11 signal of the warm meddy $A$ (station 605). Although meddies A and B exhibit about the same salinities (Figure $4 b$ ), B (station 555) is significantly colder and poorer in F11 compared with meddy $A$. The two stacked MW cores present near the Iberian shelf (Figure 3) exhibit F1l concentrations of $1.66 \mathrm{pmol} / \mathrm{kg}(800 \mathrm{dbar}, \mathrm{Mu})$ and $1.1 \mathrm{pmol} / \mathrm{kg}(1100-1400 \mathrm{dbar}, \mathrm{Ml})$. The origin of the high F11 concentrations in the MW tongue was studied by Rhein and Hinrichsen [1993]; they showed that mixing of outflowing Gibraltar water with overlying North Atlantic Central Water from depth $>200 \mathrm{dbar}$ in the Gulf of Cadiz is mainly responsible for the observed FII profiles. The temperature, salinity, and F11 data in the Gulf of Cadiz are positively correlated within the MW tongue. Admixture of North Atlantic Central Water from different depths into Gibraltar water provides the higher F11 and relatively lower salinity signature of $\mathrm{Mu}$. The higher F11 concentrations below the salinity maximum of the background station 548 typical for the region west of $15^{\circ} \mathrm{W}$ show a greater influence of recently ventilated Subpolar Mode Water $\left(5^{\circ}<\theta<7.5^{\circ} \mathrm{C}\right)$.

\section{MEan Property Distribution AND ITS Classification}

Next we discuss spatially averaged $\theta / \mathrm{F} 11, S / \mathrm{F} 11$ and $\theta / S$ diagrams (Figures $5 a, 5 b$, and $5 c$ ). The data shown have 

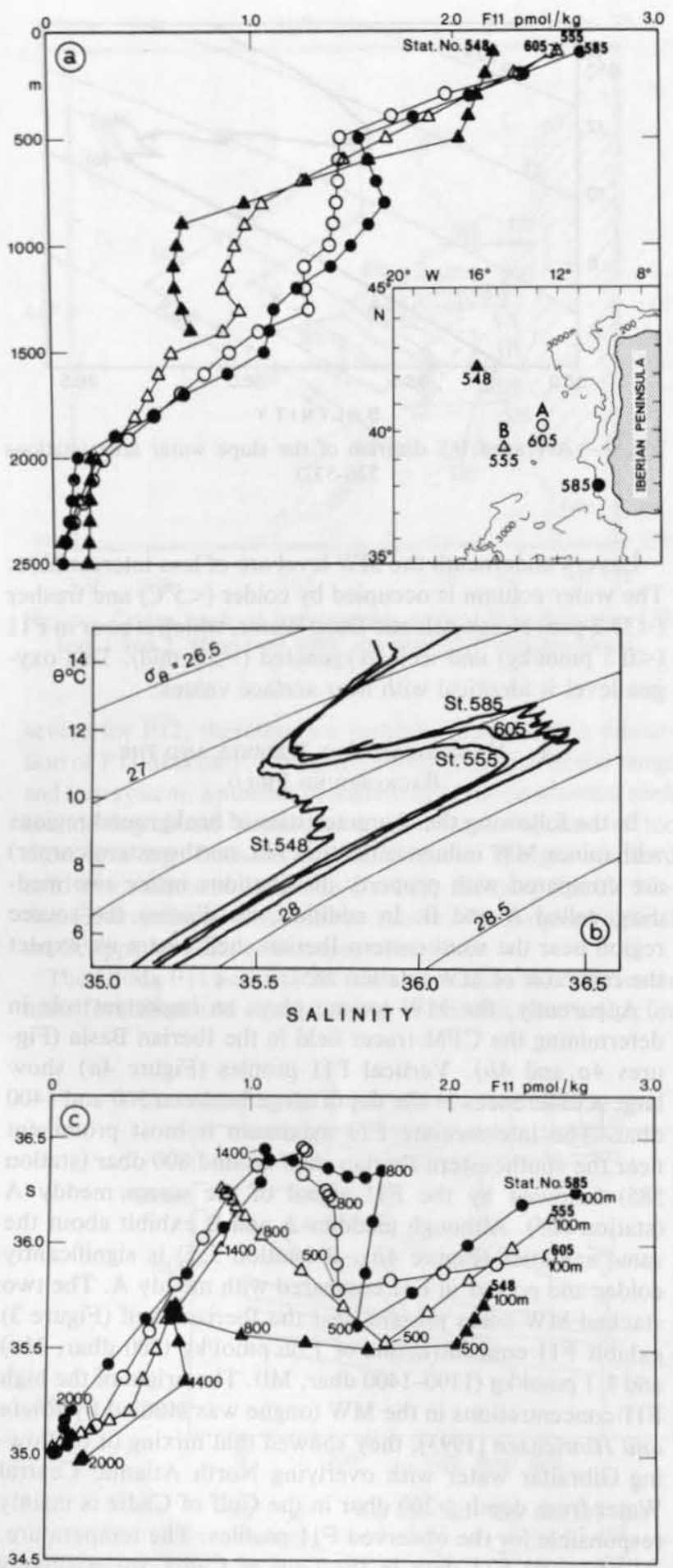

Fig. 4. (a) F11 profiles, (b) $\theta / S$ diagram, and (c) F11/S diagrams for selected hydrographic stations 548 (solid triangles), 555 (open triangles), 585 (solid circles), and 605 (open circles). Symbols represent data interpolated in 100 -dbar steps.

been separated into three groups. The first two represent stations east (dashed lines) and west (solid lines) of $15^{\circ} \mathrm{W}$. The third group contains stations with an intermediate salinity-maximum $>36.25$ psu, being representative for the highly saline Mediterranean core layer (dots). The contrast between the western and eastern parts emphasizes the significant difference of the MW influence in the Iberian
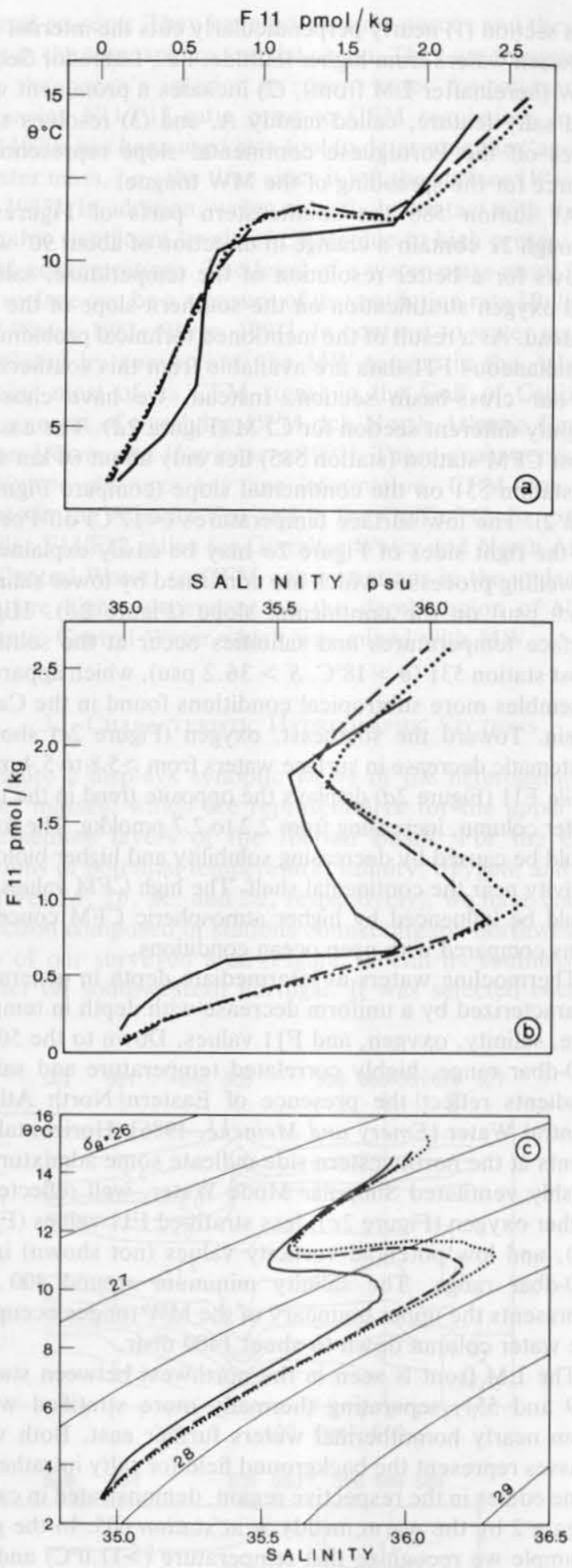

Fig. 5. Averaged parameters for stations east of $15^{\circ} \mathrm{W}$ (dashed lines), west of $15^{\circ} \mathrm{W}$ (solid lines) and for stations with intermediate salinity maxima $>36.25$ psu (dots): (a) $\theta / \mathrm{F} 11$ diagrams, (b) $S / \mathrm{F} 11$ diagrams; and (c) $\theta / S$ diagrams.

Basin. Owing to mixing and advection of Atlantic water the salinity maximum typically is reduced by $0.4-0.5$ psu corresponding to a decrease of $0.4 \mathrm{pmol} / \mathrm{kg}$ in the $\mathrm{F} 11$ concentration (Figure $5 b$ ). This also points to further admixture of North Atlantic Deep Water to the MW in the temperature range $4^{\circ}-9^{\circ} \mathrm{C}$. The difference in the averaged $\theta / \mathrm{F} 11$ correla- 
tion between stations with $S>36.25$ psu and stations east of $15^{\circ} \mathrm{W}$ is marginal. F11 concentrations between 0.8 and 1.8 $\mathrm{pmol} / \mathrm{kg}$ are found in the temperature region between 11 and $11.5^{\circ} \mathrm{C}$, which can characterize MW (lower F11 values) but also North Atlantic Central Water (higher F11 values). West of $15^{\circ} \mathrm{W}$ the presence of Subpolar Mode Water produces higher F11 values [Pickart, 1992] for the temperature range below $9^{\circ} \mathrm{C}$ compared to the east of $15^{\circ} \mathrm{W}$.

\section{Horizontal Distributions}

Horizontal maps of observed parameters were constructed by an objective analysis routine, excluding the two-dimensional bilinear trend of the data. Generally, an isotropic covariance function with a correlation scale of 100 $\mathrm{km}$ is used. It was assumed that the error variance amounts to $15 \%$ of the total variance of the field due to measurement errors and small scale noise.

The horizontal distribution of the salinity maximum is presented in Figure $6 a$. Its depth rises from about $1400 \mathrm{~m}$ off the shelf to $900-1000 \mathrm{~m}$ in the west of the observation area (Figure $6 b$ ). Gradients run mainly parallel to the Iberian shelf, where salinity maxima exceeding 36.4 psu have been found. The highest F11 concentrations $(>1 \mathrm{pmol} / \mathrm{kg})$ on the salinity maxima surface have been measured in the southeastern corner near $12^{\circ} \mathrm{W}, 37.5^{\circ} \mathrm{N}$ (Figure $6 c$ ) coincident with the highest salinity values. The two large positive salt anomalies $(>36.25 \mathrm{psu})$ located around $13^{\circ}$ and $15^{\circ} \mathrm{W}$ at $40^{\circ} \mathrm{N}$ refer to meddies A and B described above. Depending on their different potential temperature, the warmer salt anomaly with higher temperatures is also prominent in F11, whereas the colder one at $15^{\circ} \mathrm{W}$ exhibits no unique $\mathrm{F} 11$ feature and is embedded in the salty tongue extending toward the west. A tongue of F11 poor, relatively fresh water intrudes at about $10^{\circ} \mathrm{W}$ from the north toward the shelf, and the F11 minimum at about $39^{\circ} \mathrm{N}, 13^{\circ} \mathrm{W}$, corresponds to a fresh tongue intruding from the northwest.

The LM front in the west is well documented in the salinity distribution by sharp northeast-southwest oriented gradients. This front can be identified by the 36.0 psu contour line separating the high-salinity $\mathrm{MW}$ in the east from the influence of Subpolar Mode Water in the west. Although related to shallower layers it coincides very well with sharp horizontal gradients of salinity as well as with the potential vorticity distribution [Talley and McCartney, 1982] related to the spreading of Labrador Sea Water.

The background field with less influence of $\mathrm{MW}$ in the west exhibits F11 values around $0.6 \mathrm{pmol} / \mathrm{kg}$. The F11 maximum at $39^{\circ} 30^{\prime} \mathrm{N}$ and $18^{\circ} \mathrm{W}$ is obviously too high and not correlated with salinity and/or temperature. It relates to measurements of only that station (station 542), but from the analytical point of view the data could not be rejected.

Figure 7 displays the horizontal radial speed distribution on a cross section through meddy A centered at approximately $130 \mathrm{~km}$. The inner part with its sign change between kilometers 100 and 160 resembles strongly a solid body rotation which recently has been documented by Pegasus profiles in the Canary Basin [Schultz-Tokos and Rossby, 1991]. Typical azimuthal velocities in the MW level are of the order of $10-20 \mathrm{~cm} / \mathrm{s}$. It is noteworthy that there exist velocity maxima at middepth solely connected with anticyclonic features. The term "meddy," first introduced by McDowell and Rossby [1978], is not uniquely defined. Usu-
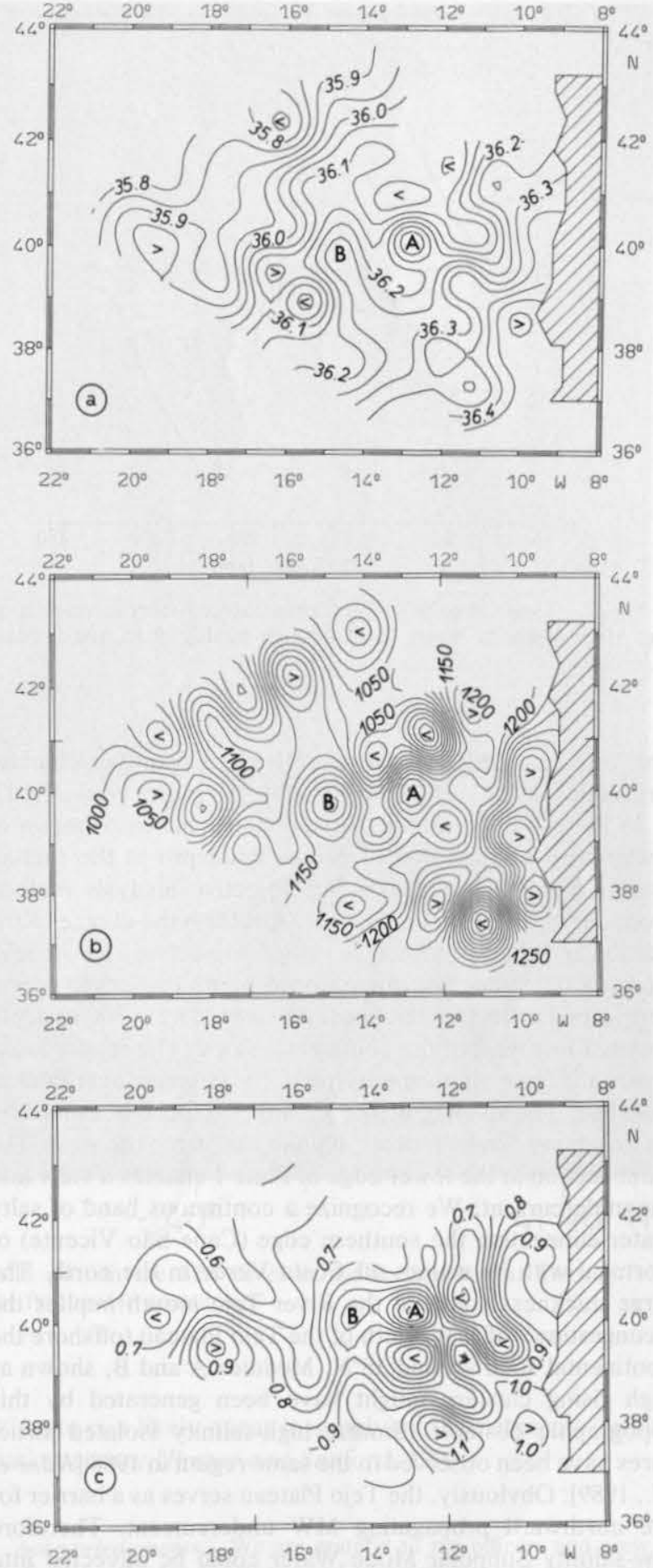

Fig. 6. Objective analysis of $(a)$ the salinity maximum between 500 and $1500 \mathrm{dbar},(b)$ the depth of the salinity maximum; and (c) the F11 distribution on the salinity maximum level.

ally, meddies are long-lived submesoscale vortices [McWilliams, 1985]. However, in a recent study of historical data, Richardson et al. [1991] regard salinity anomalies greater than a local threshold value as potential meddies. The geostrophic stream function (essentially the dynamic topography weighted inversely with the Coriolis parameter) for a near-surface layer and the MW level is shown in Figure 8. It is remarkable that even with a reference level of 2000 dbar, the dynamic signals of the observed MW eddies reach 


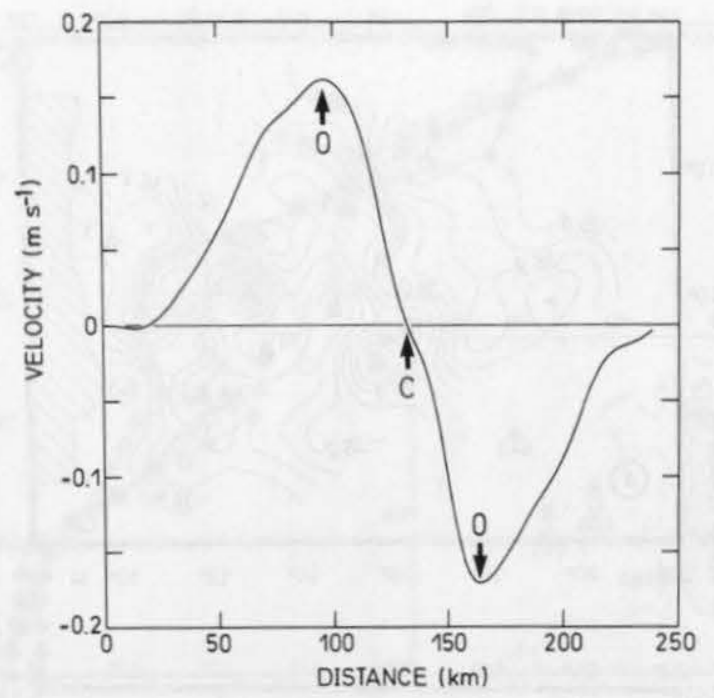

Fig. 7. Cross section of the azimuthal geostrophic velocity in the Mediterranean Water level through meddy A (o, outer edge; c, center).

the surface. Meddies can be related to positive altimeter anomalies in the surface topography [Stammer et al., 1991].

In Plate 1 we show the three-dimensional distribution of water with salinity $>36.15$ psu at middepth in the Iberian Basin. It was estimated by an objective analysis method from our quasi-synoptic data set. Although the choice of the particular salinity surface is rather subjective, we believe that it is adequate for our purpose here. The graph represents a box of 1000-m thickness downward from 500-m depth situated just west of the continental slope. The reader looks westward from an imaginary platform in space over central Portugal. The shading of the salinity structure is caused by an imaginary "light source" illuminating from the west. The front section at the lower edge of Plate 1 enables a view into the undercurrent. We recognize a continuous band of salty water connecting the southern edge (Cape São Vicente) of Portugal with its waters off Costa Verde in the north. The large thickness south of the River Tejo mouth implies the "congestion" of MW south of the Tejo Plateau (offshore the continental shelf around $38^{\circ} \mathrm{N}$. Meddies A and B, shown as high rising clusters, might have been generated by this topographic obstacle. Similar high-salinity isolated structures have been observed in the same region in 1988 [Käse et al., 1989]. Obviously, the Tejo Plateau serves as a barrier for the northward propagating MW undercurrent. Therefore low-salinity Subpolar Mode Water could be advected into the northwestern corner of the observation area.

\section{Summary and Conclusions}

Variability of water masses within the Iberian Basin is documented by hydrographic observations, enhanced by CFM and oxygen measurements. The surveyed area reveals the existence of an internal front between water masses from higher latitude and the Mediterranean Water outflow and furthermore the Portuguese continental slope as source region for the spreading of the Mediterranean Water tongue. MW in the Gulf of Cadiz is separated in two intermediate salty and warm cores corresponding to their equilibrium layers near Cape São Vicente, i.e., 700-900 m for $\mathrm{Mu}$ and around $1200 \mathrm{~m}$ for Ml. Comparisons of property correlations for both cores also provide strong splitting into these features within the Iberian Basin but are most pronounced near the shelf [Zenk and Armi, 1990], where unfortunately not many CFM measurements exist. The upper core deposits high amounts in oxygen and F11, which indicates enhanced mixing with the upper North Atlantic Central Water. The path of the mixing line could be traced back to Cape São Vicente and potentially into the Gulf of Cadiz, which confirms the representation of a continuous Mediterranean Water flow along the Iberian shelf break [Ambar and Howe, 1979; Zenk, 1975].

By means of an eddy-resolving grid in the central Iberian Basin we identified and confirmed the dominance of two mesoscale subsurface eddies. Both meddies exhibit about the same salinity, but differ strongly in temperature and F11 concentrations. Mixing of overlying North Atlantic Central Water from different depths is mainly responsible for these discrepancies. Higher F11 concentrations underneath the depth of the salinity maximum of the "background stations" further west typically correspond to the greater influence of the recently ventilated Subpolar Mode Water. Typical averaged vertical profiles and horizontal maps show the division between several characteristic water masses, coincident with the LM front, separating Mediterranean from Subpolar Mode Water, located around $15^{\circ} \mathrm{W}$.

Horizontal and vertical temperature and salinity distribu-
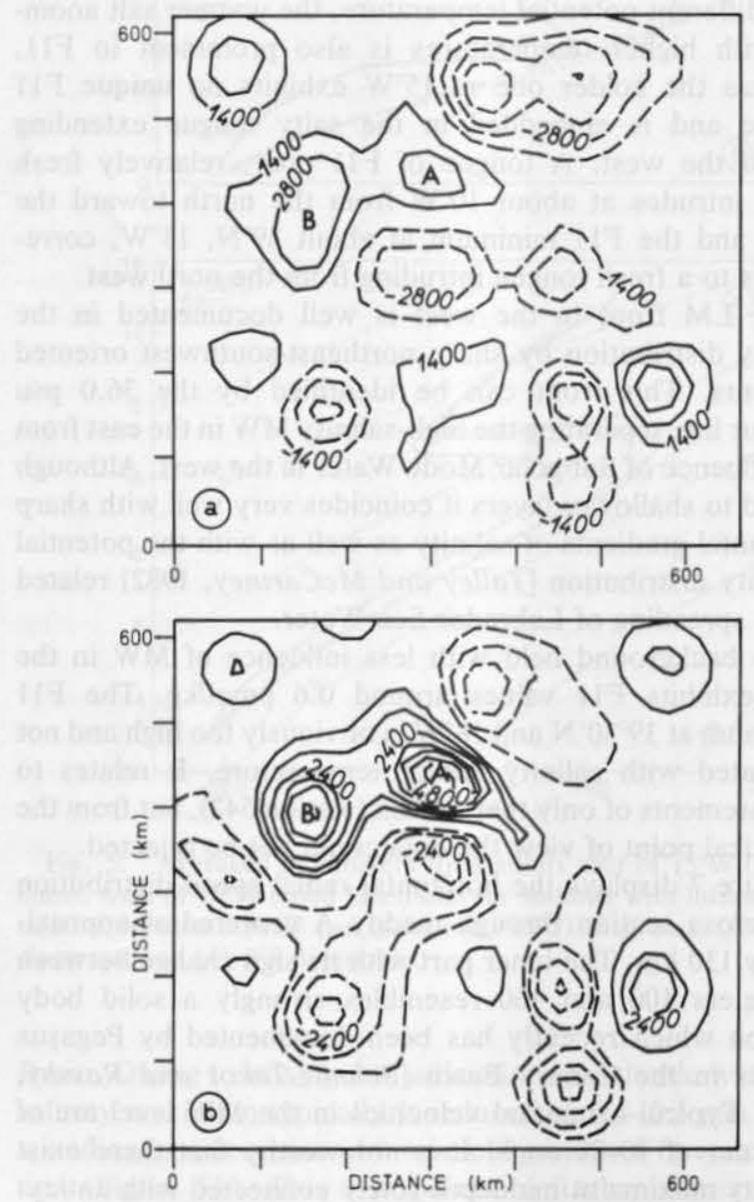

Fig. 8. Initial field of the geostrophic stream function (square meters per second): $(a)$ surface layer and $(b)$ MW layer (1200 dbar). 


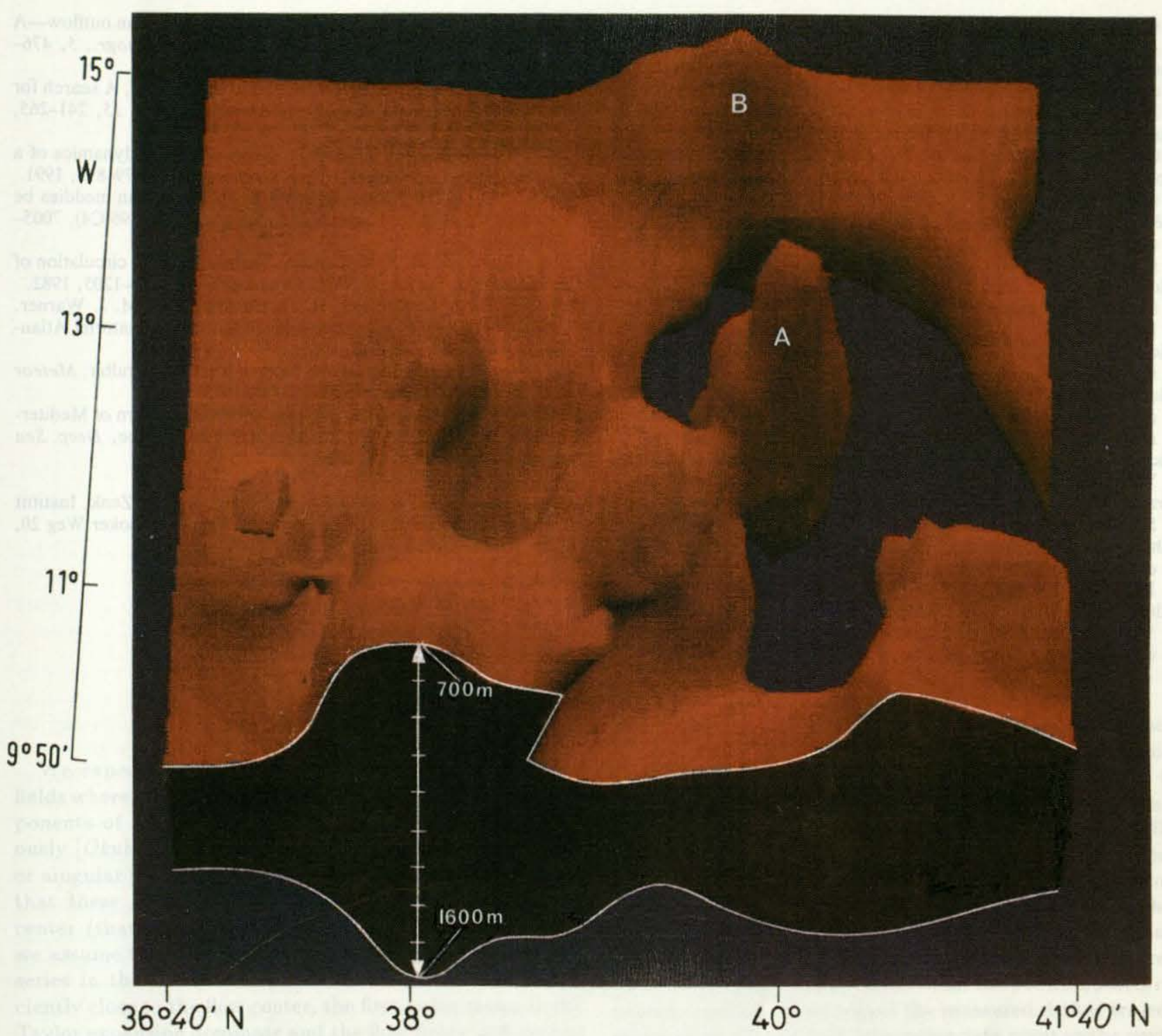

Plate 1. Three-dimensional representation of salinity $(>36.15 \mathrm{psu})$ in the MW level in the Iberian Basin. The viewpoint is located above the Portuguese coastline.

tions in the Mediterranean Water level reflect the dynamical activity of water mass differences determined by meddies and advection. They typically lead to geostrophic velocity maxima of $10-20 \mathrm{~cm} / \mathrm{s}$ apparent only in combination with anticyclonic vortices.

These observations as well as numerical simulations suggest [McWilliams and Gent, 1986; Beckmann and Käse, 1989] that meddies originate from instability of the Mediterranean undercurrent at the continental slope [Käse et al., 1989], possibly triggered and enhanced by the irregularities at middepth of the bottom topography, i.e., canyons near Cape São Vicente or the Tejo Plateau.

The general tendency of meddy movement suggests that meddies originate at the continental slope. As is shown in the three-dimensional view of the salinity (Plate 1) it could be possible that the irregularity of the eastern boundary connected with the Tejo Plateau might trigger a detachment of meanders of the northward flowing Mediterranean Water plume. Also the sharp bend of the coastline near Cape São
Vicente is a likely agent in supplying the necessary perturbation energy [Prater and Sanford, 1990].

Acknowledgments. We are grateful to the officers and crew of F. S. Poseidon for assistance and technical support during cruise 159. A. Schurbohm and A. Eisele carefully prepared the figures. T. Elbrächter performed many of the CFM analyses. The work was supported by the Deutsche Forschungsgemeinschaft (SFB 133 "Warmwassersphäre des Atlantiks").

\section{REFERENCES}

Ambar, I., A shallow core of Mediterranean Water off western Portugal, Deep Sea Res., Part A, 30(6), 677-680, 1983.

Ambar, I., and M. R. Howe, Observations of the Mediterranean outflow, I, Mixing in the Mediterranean outflow, Deep Sea Res., 26, 535-554, 1979.

Armi, L., D. Hebert, N. Oakey, J. Price, P. L. Richardson, T. Rossby, and B. Ruddick, Two years in the life of a Mediterranean salt lens, J. Phys. Oceanogr., 19, 354-370, 1989.

Beckmann, A., and R. H. Käse, Numerical simulation of the 
movement of a Mediterranean water lens, Geophys. Res. Lett., $16,65-68,1989$.

Bullister, J. L., and R. F. Weiss, Anthropogenic chlorofuoromethanes in the Greenland and Norwegian Sea, Science, 221, 265-268, 1983.

Bullister, J. L., and R. F. Weiss, Determination of CC13F and CC12F2 in seawater and air, Deep Sea Res., 35, 839-853, 1988.

Emery, W. J., and J. Meincke, Global water masses: Summary and review, Oceanol. Acta, 9, 383-391, 1986.

Käse, R. H., A. Beckmann, and H. H. Hinrichsen, Observational evidence of salt lens formation in the Iberian Basin, J. Geophys. Res., 94(C4), 4905-4912, 1989.

McDowell, S. E., and H. T. Rossby, Mediterranean water: An intense mesoscale eddy off the Bahamas, Science, 202, 10851087, 1978.

McWilliams, J. C., Submesoscale coherent vortices in the oceans, Rev. Geophys., 23, 165-182, 1985.

McWilliams, J. C., and P. R. Gent, The evolution of sub-mesoscale coherent vortices on the beta-plane, Geophys. Astrophys. Fluid Dyn., 35, 235-255, 1986.

Pickart, R. S., Water mass components of the North Atlantic Deep Western Boundary Current, Deep Sea Res., 39, 1553-1572, 1992.

Prater, M. D., and T. B. Sanford, Generation of meddies off Cape St. Vincent, Portugal (abstract), Eos Trans. AGU, 71, 1416, 1990.

Rhein, M., Ventilation rates of the Greenland and Norwegian seas derived from distributions of the chlorofluoromethanes F11 and F12, Deep Sea Res., 38, 485-503, 1991.

Rhein, M., and H. H. Hinrichsen, Modification of Mediterranean Water in the Gulf of Cadiz, studied with hydrographic and chlorofluoromethanes data, Deep Sea Res., 40, 267-291, 1993.
Richardson, P. L., and K. Mooney, The Mediterranean outflow-A simple advection-diffusion model, J. Phys. Oceanogr., 5, 476$482,1975$.

Richardson, P. L., M. S. McCartney, and C. Maillard, A search for meddies in historical data, Dyn. Atmos. Oceans, 15, 241-265, 1991.

Schultz-Tokos, K., and T. Rossby, Kinematics and dynamics of a Mediterranean salt lens, J. Phys. Oceanogr., 21, 879-892, 1991.

Stammer, D., H. H. Hinrichsen, and R. H. Käse, Can meddies be detected by satellite altimetry?, J. Geophys. Res., 96(C4), 70057014,1991 .

Talley, L. D., and M. S. McCartney, Distribution and circulation of Labrador Sea Water, J. Phys. Oceanogr., 12, 1189-1205, 1982.

Weiss, R. F., J. L. Bullister, R. H. Gammon, and M. J. Warner, Atmospheric chlorofluoromethanes in the deep equatorial Atlantic, Nature, 314, 608-610, 1985.

Zenk, W., On the Mediterranean outflow west of Gibraltar, Meteor Forschungsergeb. Ser. A., 16, 23-34, 1975.

Zenk, W., and L. Armi, The complex spreading pattern of Mediterranean Water off the Portuguese continental slope, Deep Sea Res., 37(12), 1805-1823, 1990.

H.-H. Hinrichsen, R. H. Käse, M. Rhein, and W. Zenk, Institut für Meereskunde an der Universität Kiel, Düsternbrooker Weg 20, D-2300 Kiel 1, Germany.

(Received November 7, 1991; revised November 15, 1992; accepted December 15, 1992.) 